\title{
Satellite-based evidence of wavelength-dependent aerosol absorption in biomass burning smoke inferred from Ozone Monitoring Instrument
}

\author{
H. Jethva ${ }^{1}$ and O. Torres ${ }^{2}$ \\ ${ }^{1}$ Department of Atmospheric \& Planetary Sciences, Hampton University, Hampton, VA 23668, USA \\ ${ }^{2}$ NASA Goddard Space Flight Center, Greenbelt, MD, 20771, USA
}

Received: 15 February 2011 - Published in Atmos. Chem. Phys. Discuss.: 2 March 2011

Revised: 12 September 2011 - Accepted: 22 September 2011 - Published: 25 October 2011

\begin{abstract}
We provide satellite-based evidence of the spectral dependence of absorption in biomass burning aerosols over South America using near-UV measurements made by the Ozone Monitoring Instrument (OMI) during 2005-2007. In the current near-UV OMI aerosol algorithm (OMAERUV), it is implicitly assumed that the only absorbing component in carbonaceous aerosols is black carbon whose imaginary component of the refractive index is wavelength independent. With this assumption, OMI-derived aerosol optical depth (AOD) is found to be significantly over-estimated compared to that of AERONET at several sites during intense biomass burning events (August-September). Other wellknown sources of error affecting the near-UV method of aerosol retrieval do not explain the large observed AOD discrepancies between the satellite and the ground-based observations. A number of studies have revealed strong spectral dependence in carbonaceous aerosol absorption in the near-UV region suggesting the presence of organic carbon in biomass burning generated aerosols. A sensitivity analysis examining the importance of accounting for the presence of wavelength-dependent aerosol absorption in carbonaceous particles in satellite-based remote sensing was carried out in this work. The results convincingly show that the inclusion of spectrally-dependent aerosol absorption in the radiative transfer calculations leads to a more accurate characterization of the atmospheric load of carbonaceous aerosols. The use of a new set of aerosol models assuming wavelength-dependent aerosol absorption in the nearUV region (Absorption Angstrom Exponent $\lambda^{-2.5}$ to -3.0 ) improved the OMAERUV retrieval results by significantly
\end{abstract}

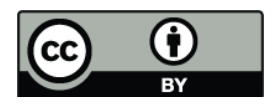

Correspondence to: $\mathrm{H}$. Jethva (hiren.jethva@hamptonu.edu) reducing the AOD bias observed when gray aerosols were assumed. In addition, the new retrieval of single-scattering albedo is in better agreement with those of AERONET within the uncertainties $(\triangle S S A= \pm 0.03)$. The new colored carbonaceous aerosol model was also found to reproduce the ground-based AOD observations over the biomass burning region of central Africa and northern India. Together with demonstrating a significant improvement in the retrieval of aerosol properties from OMI, the present study highlights the greater sensitivity of the near-UV measurements to the varying spectral aerosol absorption. This capability can be explored further for the use in the identification of the black carbon and organics in the biomass burning aerosols.

\section{Introduction}

Biomass burning is a major source of carbonaceous aerosols in several regions of the world, the tropics in particular, where it contributes a significant fraction of the observed aerosol optical depth, AOD, (Venkataraman et al., 2005; Chand et al., 2006) The Amazonia region in South America accounts for about one third of total biomass burning activities in the tropics most of which takes place during the August-October period (Chand et al., 2006). The emission of huge amount of aerosols during these events changes the physical and optical properties of aerosols dramatically relative to the background level over this region (Guyon et al., 2003). The aerosols produced by biomass burning contain dominant carbonaceous compounds such as black carbon (BC) or soot, and organic carbon (OC) also referred to as brown carbon (Andrea and Gelencsér, 2006). While BC is the most efficient known absorber of light in atmosphere,

Published by Copernicus Publications on behalf of the European Geosciences Union. 
the evidence on the presence of OC in the biomass burning aerosols has been presented by several studies (Kirchstetter et al., 2004; Bergstrom et al., 2007; Russell et al., 2010). These studies show that though the wavelength dependence of $\mathrm{BC}$ and $\mathrm{OC}$ absorption is spectrally flat at wavelengths longer than about $600 \mathrm{~nm}, \mathrm{OC}$ aerosol absorption departs from spectral neutrality in the blue and near UV regions where a steep increase in absorption with decreasing wavelength is observed. Because of the radiative impacts on the Earth's radiation budget and climate, carbonaceous aerosols have received a great amount of attention by the atmospheric science community.

The aerosol physical and optical properties and associated spatial and temporal variability over the Amazon basin have been studied and reported by several investigations using ground-based, suborbital (Eck et al., 1998; Martins et al., 1998; Reid et al., 1998) as well as satellite observations (Koren et al., 2007; Torres et al., 2010). In addition to aerosol data collected during specific field campaigns, the sunphotometers installed as a part of AErosol RObotic NETwork (AERONET) at several sites in the region also provide remotely sensed high quality data on aerosol optical properties (Holben et al., 1998).

Multi-year long data records on aerosol optical depth collected from several satellite borne sensors like Total Ozone Measuring Spectrometer (TOMS) (Torres et al., 2002), Moderate-resolution Imaging Spectroradiometer (MODIS) (Remer et al., 2005; Levy et al., 2007), Multiangle Imaging Spectroradiometer (MISR) (Kahn et al., 2005), and Ozone Monitoring Instrument (OMI) (Torres et al., 2007; Ahn et al., 2008) document the long-term evolution of the carbonaceous aerosol load associated with the burning of forest and agricultural waste in Amazonia. Because of the known sensitivity of near-UV observations to aerosol absorption (Torres et al., 1998, 2007), satellite observations by the TOMS and OMI sensors are specially suited for the detection and characterization of $\mathrm{BC}$ and $\mathrm{OC}$ containing aerosol particles.

Figure 1 shows the September 2007 monthly mean spatial distribution of the atmospheric aerosol load over South America in terms of the Aerosol Index (AI) derived from OMI observations. AI is derived from the change in the spectral dependence of the back-scattered UV radiance induced by aerosols relative to the Rayleigh scattering between 354 and $388 \mathrm{~nm}$ (Herman et al., 1997; Torres et al., 1998, 2007). It is a useful qualitative indicator of the presence of absorbing and elevated aerosols, such as biomass burning plumes and dust aerosols. The spatial distribution of AI shows high values over the central part of South America indicating the presence of large amounts of absorbing aerosols, and relatively lower AI values towards the south.

In addition to deriving AI, OMI-measured near-UV radiances at 354 and $388 \mathrm{~nm}$ are used as input to an inversion algorithm (OMAERUV) to derive AOD and single scattering albedo (SSA) at $388 \mathrm{~nm}$. As with any aerosol inversion procedure retrievals are derived based on certain as-

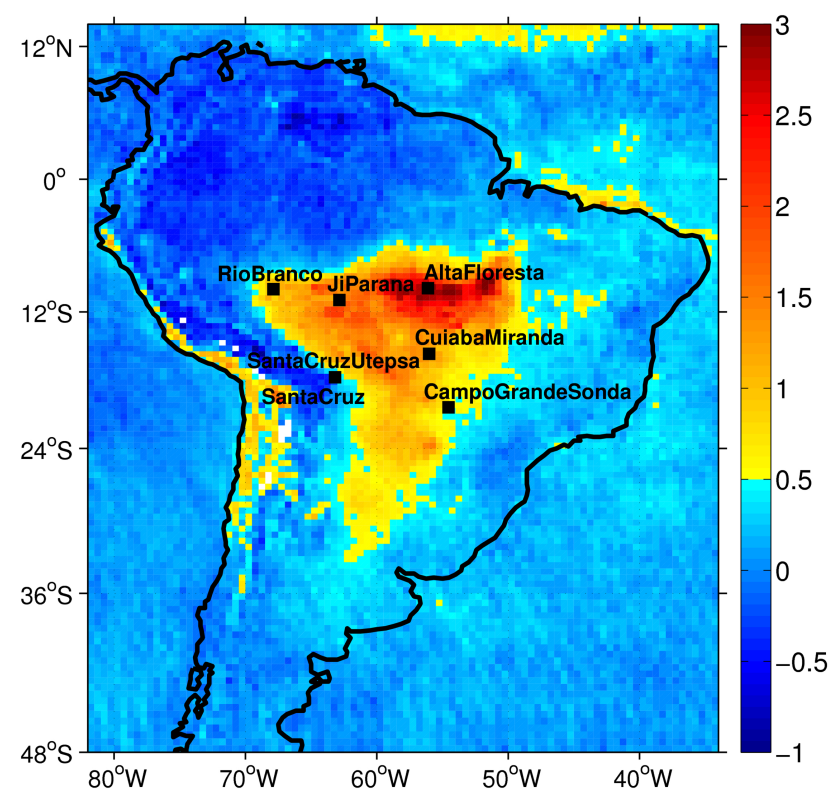

Fig. 1. Monthly mean UV aerosol index derived from OMI for September 2007 over South America. Depicted inside are locations of seven AERONET stations whose data was used in this study.

sumptions made in the algorithm; therefore, their assessment against accurate ground-based measurements is necessary. In the present study, we evaluate the OMAERUV retrieved aerosol parameters by comparison to AERONET observations over selected stations in South America's biomass burning region (see Fig. 1), and examine the implication of OMAERUV assumptions with emphasis on the spectral dependence of aerosol absorption. Section 2 briefly describes the OMAERUV aerosol inversion procedure and dataset used in the analysis. The outcome of the standard OMAERUVAERONET comparison and possible causes of the resulting differences are discussed in Sect. 3. Section 4 presents the results and interpretation of a sensitivity analysis in which the response of $\mathrm{AI}$ to varying spectral absorption has been analyzed. The findings of the limited ground-based studies on the spectral aerosol absorption are also discussed in Sect. 4. The comparison of new OMAERUV retrievals which are based on theoretical calculations and ground-based observations (Sect. 4) is presented and discussed in Sect. 5. Section 6 summarizes the results and main conclusions of the present study.

\section{A brief description of OMAERUV aerosol inversion and dataset}

The UV part of the solar spectrum has distinct and unique advantages for the characterization of aerosol properties. Most surfaces, including visibly bright desert appear dark due to low surface reflectivity at UV wavelengths. This is a 
favorable condition as it leads to less surface contamination in total signal at top-of-atmosphere. Secondly, multiple interactions of Rayleigh-scattered radiation with aerosols provide an opportunity to infer the aerosol absorption under clear as well as cloudy conditions (Torres et al., 1998, 2007).

OMI is a successor of the TOMS series of instruments with hyper-spectral imaging capability at higher spatial resolution $\left(13 \times 24 \mathrm{~km}^{2}\right.$ at nadir) than other UV-capable sensors [GOME, GOME-2 SCIAMACHY]. OMI takes advantage of the greater sensitivity of near-UV radiances to the varying load and types of aerosols to derive extinction aerosol optical depth, SSA at $388 \mathrm{~nm}$, and absorption AOD using an inversion procedure. Currently, the OMAERUV algorithm assumes a set of "gray" aerosol models, meaning there is no wavelength dependence in absorption (i.e. imaginary refractive index), to derive aerosol properties over the biomass burning regions. These models are representative of aerosol types whose absorption properties are mainly driven by the presence of black carbon. The associated particle size distributions were adopted from multi-year AERONET measurements over the major biomass burning regions of the world (Torres et al., 2007). Near UV surface albedo is prescribed making use a TOMS-based monthly climatology similar to that of Herman and Celarier (1997) in which the minimum reflectivity over a 14-yr period is assumed to be an adequate representation of the actual surface with minimum aerosol and cloud interference. In the tropics, the aerosol profile is represented as a single layer with aerosol number density concentration described by a Gaussian distribution of peak concentration at $3 \mathrm{~km}$. Using these assumptions as an input to the radiative transfer code, the top-of-atmosphere radiances at 354 and $388 \mathrm{~nm}$ are generated at several geometries and varying $f$ aerosol optical depth (AOD) and single scattering albedo (SSA). Thus, a set of measured radiances at two UV wavelengths is associated with a set of AOD and SSA values. The retrieved aerosol parameters are converted to 354 and $500 \mathrm{~nm}$ using the spectral dependence associated with the assumed aerosol model.

The OMAERUV algorithm uses a combination of the observed Lambertian Equivalent Reflectivity (LER) at $388 \mathrm{~nm}$ $\left(R_{388}\right)$; the difference between top of the atmosphere measured reflectivity and surface reflectivity $(\Delta R)$; and the Aerosol Index in a scheme to assign a flag number to each retrieval which classifies the quality of the retrieval product in terms of the level of sub-pixel cloud contamination. As per the current quality flag scheme, retrievals flagged 0 ( $\Delta R \leq 0.04$ for dust and sulphate; $\Delta R \leq 0.08$ for biomass burning, and UVAI $\geq 1.0 ; \Delta R=$ TOA reflectivitysurface reflectivity) are considered minimally affected by sub-pixel cloud contamination, whereas retrievals with flag $1\left(R_{388}<0.30\right.$ and $\left.\mathrm{UVAI} \geq 1.2\right)$ are deemed to be affected by sub-pixel cloud contamination and therefore the reported AOD and SSA values are not reliable. A more detailed description of the OMI UV aerosol algorithm is presented in Torres et al. (2007). We use the OMI Level 2 OMAERUV
Collection 3 aerosol product, including aerosol optical depth at $388 \mathrm{~nm}$, UV aerosol index, single-scattering albedo, and radiance at these channels in our analysis. The spatial resolution of these datasets is $13 \times 24 \mathrm{~km}^{2}$ at nadir. We have considered aerosol retrievals with quality flag 0 and 1 when comparing against AERONET measurements.

AERONET is a ground-based worldwide network of Cimel sunphotometers that measure the extinction aerosol optical depth at seven wavelengths $(340,380,440,500,670$, $870,1020 \mathrm{~nm}$ ) using the direct sun measurements (Holben et al., 1998). The AOD measurements are accurate to within \pm 0.01 in the visible and \pm 0.02 in the near-UV (Holben et al., 1998). AERONET also retrieves aerosol optical and particle size distribution properties by fitting the direct sun AOD measurements and angular sky radiance at four wavelengths $(440,675,870,1020 \mathrm{~nm})$ to radiative transfer calculations (Dubovik and King, 2000). In this study, we use AERONETderived Level 2.0 (cloud-screened and quality assured) AOD and SSA for the evaluation of OMAERUV aerosol retrievals over South America, central Africa, and northern India.

The validation of OMI aerosol products is an ongoing activity. Torres et al. (2007) compared the OMIderived AOD with that of AERONET direct sun measurements and found that under minimum cloud interference the OMAERUV retrievals agree well with AERONET AOD observations yielding root-mean-square error $=0.26$ and correlation $=0.74$. OMAERUV-AERONET comparison of derived SSA indicates that $73 \%$ of the analyzed OMAERUV SSA retrievals were within \pm 0.05 of AERONET inversions. Ahn et al. (2008) have compared the OMI-derived AOD with that of MODIS and MISR and found that in spite of a positive offset of 0.15 , the OMI retrievals showed a high degree of correlation with the two independently derived quantities. Also, OMI was found to capture the seasonal and annual cycles of aerosols over major biomass burning and mineral dust emission sources.

\section{Evaluation of standard OMAERUV aerosol optical depth over South America}

\subsection{OMAERUV vs. AERONET comparison}

A comparison of OMI-derived with AERONET-measured AOD's was carried out over a four-year period (2005-2008) at the seven AERONET sites in Table 1. For the comparison of the spatial satellite retrievals with point measurements, we adopted a collocation scheme in which the OMAERUV retrievals were averaged in a grid box of size $0.5^{\circ}$ by $0.5^{\circ}$ centered at AERONET site and compared them with the temporally averaged AERONET measurements within $\pm 30 \mathrm{~min}$ of OMI overpass. Also, note that the AERONET AOD measurements are available at $340 \mathrm{~nm}$ and $380 \mathrm{~nm}$ in the nearUV and $440 \mathrm{~nm}$ in the visible. Therefore, using the Extinction Angstrom Exponent in this range the AERONET 
Table 1. Geolocation data and mean aerosol optical depth at $500 \mathrm{~nm}$ at seven AERONET station in South America.

\begin{tabular}{lccccc}
\hline Station Name & Latitude & Longitude & $\begin{array}{c}\text { Elevation } \\
\text { (in meters) }\end{array}$ & Data period & $\begin{array}{c}\text { Mean AERONET } \\
\text { AOD (500 nm) }\end{array}$ \\
\hline Alta Floresta & -9.871 & -56.104 & 277 & Oct 2004-Dec 2007 & 0.93 \\
Rio Branco & -9.957 & -67.869 & 212 & Oct 2004-Feb 2008 & 0.95 \\
Ji Parana & -10.934 & -62.852 & 218 & Jun 2006-Sep 2008 & 0.74 \\
Cuiaba Miranda & -15.729 & -56.021 & 210 & Oct 2004-Nov 2007 & 0.73 \\
Santa Cruz Utepsa & -17.767 & -63.201 & 432 & Sep 2006-Oct 2007 & 0.80 \\
Santa Cruz & -17.802 & -63.178 & 442 & Oct 2004-Mar 2006 & 0.68 \\
Campo Grande Sonda & -20.438 & -54.538 & 677 & Oct 2004-Sep 2008 & 0.34 \\
\hline
\end{tabular}

measurements were interpolated to $388 \mathrm{~nm}$ to match with the wavelength of the OMI retrieval.

Figure 2 shows the comparison of collocated OMAERUV AOD (y-axis) with that of AERONET (x-axis) for the seven stations over South America. OMAERUV data with quality flag 0 and 1 are used in the comparison. Clearly, all OMI AOD retrievals with quality flag 1 and few with flag 0 are significantly over-estimated with respect to the AERONET measurements. Also, all retrievals with quality flag 1 fall outside the expected OMAERUV uncertainty range (larger of 0.1 or $30 \%$ ). Though, the OMI-AERONET correlation is high (0.87), the large over-estimation in quality flag 1 retrievals led to the root-mean-square error of about 1.5. While all retrievals with quality flag 1 in Fig. 2 that represent conditions of $\mathrm{AI}>1$ and $R_{388}$ up to 0.30 are collocated with higher values of AERONET AOD (up to 4 at $380 \mathrm{~nm}$ ), most data with flag value zero were confined within a lower AOD regime (AERONET AOD $<1$ ). As per the current scheme of assigning the quality flags, the OMAERUV algorithm treats the most absorbing data (flag 1) as of degraded quality. This is because the higher reflectivity is assumed to be associated with the possible sub-pixel cloud contamination. However, large values of UV-AI for these measurements indicate the presence of absorbing aerosols over those pixels. The following section discusses the extent of possible sub-pixel cloud contamination associated with high reflectivity and elevated AI cases.

\subsection{Analysis on possible causes of AERONET- OMAERUV differences}

The main source of uncertainty in the application of the nearUV technique to OMI observations is sub-pixel cloud contamination associated with the large size of the OMI footprint. The second most important source of uncertainty is the dependence on the assumed aerosol layer height. Other possible sources of error include surface albedo effects, and aerosol model assumptions on particle size distribution and refractive index. The observed AOD over-estimations, however, are too large to be simply explained by sub-pixel cloud contamination, surface reflectance effects or assumed parti-

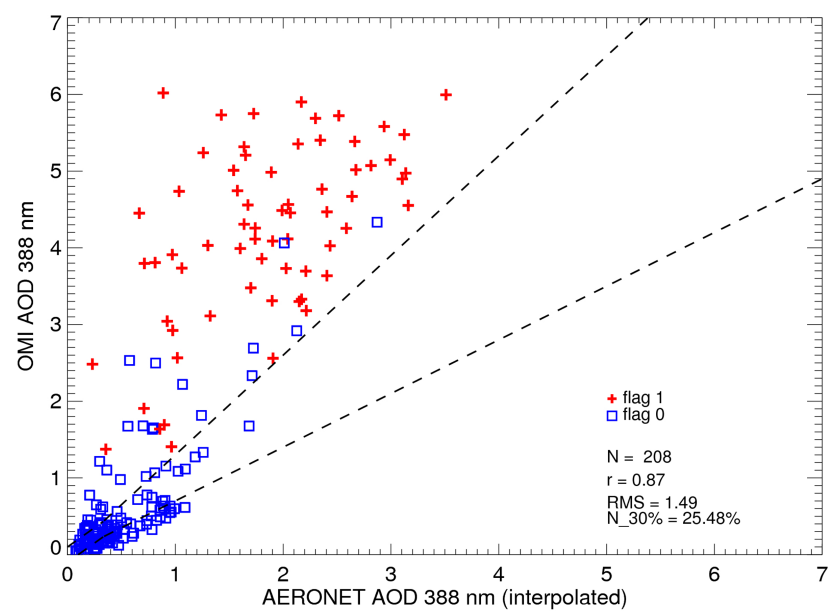

Fig. 2. Scatter-plot of the co-located aerosol optical depth $(388 \mathrm{~nm})$ between OMI (y-axis) and AERONET (x-axis) for selected seven stations over the biomass burning region of South America. OMI data with flag 0 (square) and flag 1 (plus sign) were used in the comparison. The dashed lines are pre-calculated uncertainty (larger of 0.1 or $30 \%$ ) in the OMI AOD retrieval.

cle size distribution. The surface albedo in the UV region is low compared to that in the visible region and, therefore, the error in the aerosol retrieval produced by the uncertainty associated with surface albedo is expected to be very low.

In the near UV approach of aerosol retrieval the AOD can be over-estimated if the aerosol layer height is underestimated. For carbonaceous aerosols, the AOD is overestimated by $10 \%$ per $1 \mathrm{~km}$ under-estimation (Torres et al., 1998). Thus, to explain errors of $100 \%$ and larger in terms of the prescribed aerosol height, the "actual" location of the aerosol layer would need to be at least $13 \mathrm{~km}$ above the surface which is clearly unrealistic. The assumed vertical distribution is actually consistent with direct measurements by the CALIOP lidar.

The Cloud-Aerosol Lidar and Infrared Pathfinder Satellite Observation (CALIPSO) satellite as a part of the A-train constellation measures the vertical profile of back-scattered 
radiation attenuated by clouds and aerosols over the globe. A visual inspection of several CALIPSO overpass images available at http://www-calipso.larc.nasa.gov/ over the biomass burning region show maximum back-scatter due to aerosols to be around $3 \mathrm{~km}$ height. For instance, for an aerosol event observed on 2 September 2007, the OMAERUV algorithm derives a $388 \mathrm{~nm}$ AOD of 6 in the Alta Floresta region with an UV aerosol Index of 2.29, whereas AERONET measures AOD of 3.68 at about the same wavelength. The CALIPSO overpass shows an aerosol back-scatter peak at around $3 \mathrm{~km}$ height over the same region for the same day. This suggests that the height of aerosols assumed by the OMAERUV standard algorithm is likely to be correct over this region and any small departure from the true aerosol height cannot explain the large over-estimation in OMI AOD retrieval.

Given the OMI footprint size of 13 by $24 \mathrm{~km}^{2}$, there is a possibility of the presence of sub-pixel cloud contamination. In order to verify the effect of sub-pixel size clouds, several OMAERUV-AERONET matchups were analyzed in conjunction with corresponding MODIS true-color RGB images (http://rapidfire.sci.gsfc.nasa.gov/). Figure 3 shows one such case of a smoke event observed over Alta Floresta region on 19 September 2005. This RGB image is a subset of L2 5-min swath (or granule) centered at Alta Floresta AERONET site. A box of size $0.5 \mathrm{deg}$ by $0.5 \mathrm{deg}$ shown around the center of image is the region over which the OMAERUV retrievals were extracted and compared with AERONET. In this case and several others (not shown here), the region around AERONET site visually appears to be devoid of clouds, showing instead, what appears to be a dense smoke layer. For this particular aerosol event the standard OMAERUV algorithm reported AOD 5.71 which is more than double the AERONET measurement (2.35). The cloud fraction estimated by MODIS aerosol algorithm is nil which further provides evidence of no clouds over the AERONET site. Similar results were noted for other OMI-AERONET collocated cases. Certainly, the sub-pixel could contamination in a given OMI pixel cannot explain the large overestimation seen in the standard OMAERUV product.

\section{Aerosol spectral absorption effects}

It has been discussed in the previous section that the observed large AOD overestimate cannot be explained as the result of assumptions on retrieval conditions, surface albedo, cloud contamination, or the height of aerosol layer. We will now examine the effect of the assumption on no-spectral dependence of the imaginary component of the refractive index which is an implicit assumption that $\mathrm{BC}$ is the main absorbing component. A parameter known as the Absorption Angstrom Exponent or AAE (Bond, 2001; Bergstrom et al., 2007; Russell et al., 2010) is commonly used to describe the spectral dependence of the aerosol absorption optical depth (AAOD) in a similar way that the Extinction Angstrom

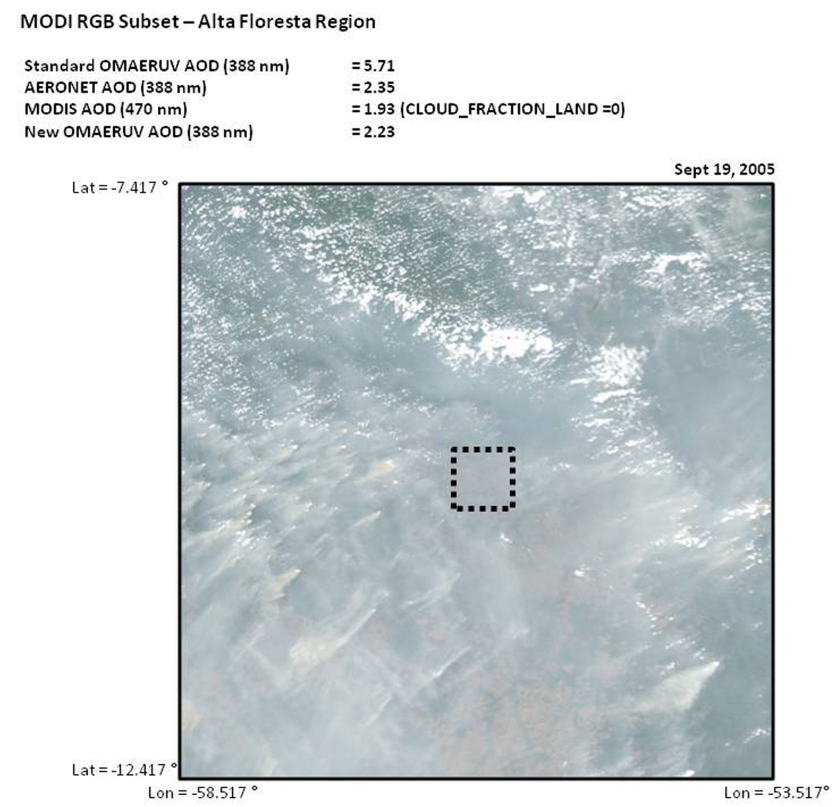

Fig. 3. A subset of MODIS true-color RGB of size $5^{\circ}$ by $5^{\circ}$ over the Alta Floresta region for 19 September 2005. A box of size $0.5^{\circ}$ by $0.5^{\circ}$ (dashed line) shown at the center of the image is the region over which the OMAERUV retrievals were extracted for the comparison with AERONET. The AOD derived by the standard OMAERUV, AERONET, MODIS, and new OMAERUV algorithms for this region is given at the top of the plot.

Exponent is used to describe the spectral dependence of the aerosol extinction optical depth. The AAOD is related to the wavelength $(\lambda)$ of the incident light by a power law fit given by,

$\mathrm{AAOD}=k \lambda^{-\mathrm{AAE}}$

where, AAE is the slope of AAOD-wavelength relation in $\log -\log$ space, and $k$ is the intercept of this relation. Theoretically, aerosol types that exhibit a wavelength independent AAOD yield AAE of 1.0 (Bond, 2001). The larger the AAE the steeper the slope of the AAOD- $\lambda$ relationship. Values larger than unity indicate spectrally dependent absorption, and can be used to infer aerosol composition. The AAE for black carbon or soot emitted from high-temperature combustion processes such as vehicle emission and urban/industrial aerosols whose wavelength-dependence of absorption can be approximated as $\lambda^{-1.0}$ in the UV-visible range (Bond, 2001; Bergstrom et al., 2002; Kline et al., 2004; Bond and Bergstrom, 2006). The original assumption of no spectrallydependent absorption in the carbonaceous aerosol models used in the OMAERUV algorithm implies that BC is considered to be the aerosol component driving the observed spectral absorption signal in the near UV. We will now examine the adequacy of this assumption. 
Table 2. The imaginary component of refractive index and associated absorption angstrom exponent $\left(\alpha_{\text {abs }}\right)$ for nil, $20 \%$ and $30 \%$ spectral dependence between 354 and $388 \mathrm{~nm}$.

\begin{tabular}{cc|cc|cc}
\hline \multicolumn{2}{c|}{ No Spectral Dependence } & \multicolumn{2}{c}{ 20\% Spectral Dependence } & 30\% Spectral Dependence \\
\hline Img. Ref. Index 388/354 & $\alpha_{\text {abs }}$ & Img. Ref. Index 388/354 & $\alpha_{\text {abs }}$ & Img. Ref. Index 388/354 & $\alpha_{\text {abs }}$ \\
\hline $0.048 / 0.048$ & 1.01 & $0.048 / 0.0576$ & 2.49 & $0.048 / 0.0624$ & 3.12 \\
$0.040 / 0.040$ & 1.03 & $0.040 / 0.0480$ & 2.54 & $0.040 / 0.0520$ & 3.20 \\
$0.030 / 0.030$ & 1.06 & $0.030 / 0.036$ & 2.62 & $0.030 / 0.0390$ & 3.29 \\
$0.020 / 0.020$ & 1.07 & $0.020 / 0.024$ & 2.67 & $0.020 / 0.0260$ & 3.37 \\
$0.010 / 0.010$ & 1.11 & $0.010 / 0.012$ & 2.84 & $0.010 / 0.0130$ & 3.60 \\
$0.005 / 0.005$ & 1.13 & $0.005 / 0.006$ & 2.92 & $0.005 / 0.0650$ & 3.70 \\
$0.000 / 0.000$ & N/A & N/A & N/A & N/A & N/A \\
\hline
\end{tabular}

\subsection{Sensitivity analysis}

The relationship between AOD and the wavelength dependent imaginary refractive index in the near UV was examined by a sensitivity analysis using radiative transfer calculations. Simulated radiances at 354 at $388 \mathrm{~nm}$ for several cases of spectrally dependent imaginary refractive index and atmospheric aerosol load were used to calculate the Aerosol Index. Table 2 lists the corresponding AAE as a function of $388 \mathrm{~nm}$ imaginary refractive index. The spectral slope in aerosol absorption was created by increasing the imaginary refractive index at $354 \mathrm{~nm}$ while keeping it constant at $388 \mathrm{~nm}$. The $0 \%$ spectral dependence in the imaginary index yields AAE values of about 1 , whereas larger AAE values between about 2.5 and 3.0 and between 3.1 and 3.7 are associated with the $20 \%$ and $30 \%$ spectral dependence respectively. Figure 4 displays the calculated AI as a function of AOD for the three assumptions of the spectral dependence in the imaginary index in the near-UV, i.e. for "gray" aerosols, and "colored" aerosols with $20 \%$ and $30 \%$ dependence respectively. Also given in the plot is the corresponding AAE value for each case. In all three cases, AI increases monotonically with AOD, however, the magnitude of the AI increases as the spectral dependence becomes larger. With the assumption of wavelength-dependent aerosol absorption, $\mathrm{AI}$ is found to be significantly higher than that computed with spectrally independent absorption for the same values of AOD. A similar result was also noted by de Graaf et al. (2005). This means that for a given observed value of AI, different AAE assumptions will result in distinct values of AOD. For instance, for an observed AI value of 2.0, the AOD derived assuming 30\%, 20\% and wavelength independent absorption would be about $0.55,0.77$, and 2.25 (also shown in the plot). Thus with the assumption of "colored aerosols" (i.e. spectrally dependent absorption), the OMI near-UV observations can be explained with lower AOD than the ones required if the gray aerosol assumption is used. The result of this analysis suggests that the near-UV retrieval of AOD is highly sensitive to the assumption about spectral aerosol absorption.

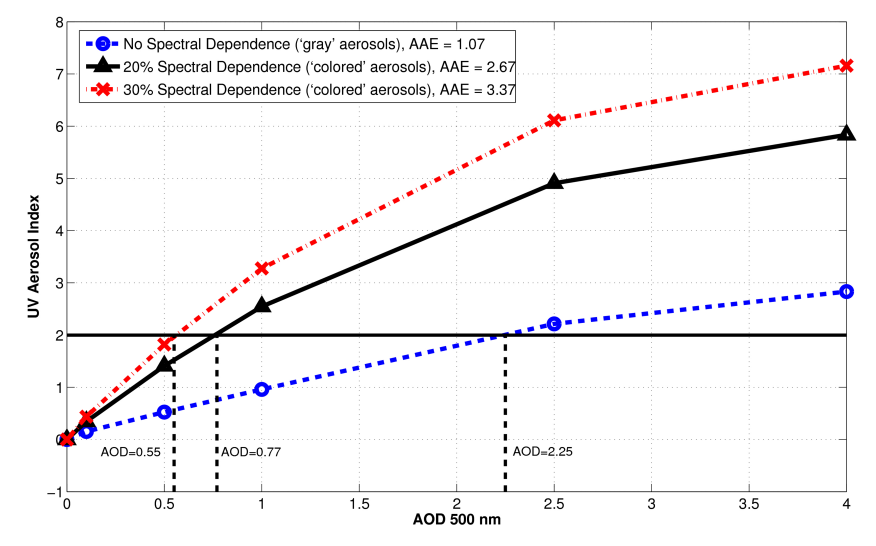

Fig. 4. UV Aerosol Index as a function of aerosol optical depth for varying spectral dependence of the aerosol absorption in the range $354-388 \mathrm{~nm}$. An arbitrary value of UV-AI (2.0) and its corresponding values of $\operatorname{AOD}(0.55,0.77$, and 2.25$)$ are also shown.

\subsection{Ground-based evidences of wavelength-dependent aerosol absorption}

Based on the results of the sensitivity analysis in the previous section we developed a new carbonaceous aerosol model in which the presence of $\mathrm{OC}$ is accounted for by allowing for spectral dependence of the imaginary refractive index. The choice of the AAOD- $\lambda$ spectral slope was based on available ground-based observations as briefly reviewed here.

Bergstrom et al. (2007) discussed the results on the spectral absorption properties of aerosols derived during several major field campaigns (TARFOX 1996, SAFARI 2000, PRIDE 2000, ACE Asia 2001, ICARTT 2004) conducted over different regions of the world to sample distinct aerosol mass. It was found that, in general, the AAE was near unity for urban pollution (TARFOX and ICARTT) and about 2.0 for biomass smoke (SAFARI 2000). Although, the spectral aerosol absorption optical depth yielded AAE which appears to be spectrally independent, it was pointed that AAE in the UV may be different than in the visible. Russell et al. (2010) 
used AERONET-derived columnar absorption aerosol optical depth (in the range $440-1020 \mathrm{~nm}$ ) to deduce the AAE over several sites that are representative of different aerosol types. They highlight that the AAE is a strong indicator of type of aerosols since the wavelength dependence of aerosols is strongly influenced by their chemical and size composition. They found that the AAE values are near 1 for aerosol dominated by urban-industrial aerosols (largely containing black carbon), with larger values of AAE for biomass burning, and highest AAE values for Saharan dust aerosols. The AAE in the range $440-670 \mathrm{~nm}$ was $\sim 1.5$ for the Amazonian forest and South American Cerrado, which are the regions of interest in the present study.

Several near-UV-specific studies directly relevant to OMI observations have also been conducted. From the work of Kirchstetter et al. (2004) it can be deduced that the AAE exponent in the range 350 -to- $400 \mathrm{~nm}$ for biomass burning aerosols samples collected during SAFARI 2000 was about 2.8. In a related study, Hoffer et al. (2006) measured AAE's as high as 6-7 in the visible to UV range for the humiclike substances (HULIS) isolated from the biomass burning aerosol samples collected over the Amazon basin during LBA-SMOCC. Due to steep increase in the specific absorption from visible to UV, HULIS contribute up to $50 \%$ to the total light absorption at $300 \mathrm{~nm}$ and $20-30 \%$ between $350-400 \mathrm{~nm}$. The later is relevant wavelength range for the OMI aerosol retrievals. Information on the spectral dependence of absorption by biomass burning aerosols specific to South America was also obtained from measurements of the columnar aerosol absorption at UV wavelengths using ground-based UV Multi-filter Rotating Shadowband Radiometer (UV-MFRSR) in Santacruz (Bolivia) during the intense biomass burning season of September 2007 (N. Krotkov, personal communication, 2009). In this field campaign direct sun and diffuse sky measurements were used to derive columnar single-scattering albedo (SSA) and aerosol absorption optical depth using the approach discussed by Krotkov et al. (2005). AAE values between 2.8 and 3.3 were obtained for the $332-368 \mathrm{~nm}$ wavelength range.

On the basis of the above discussed observational evidence the spectral slope associated with a $20 \%$ increase in the $354 \mathrm{~nm}$ imaginary refractive with respect to the value at $388 \mathrm{~nm}$ was adopted. This assumption yields AAE values that vary between 2.5 and 3.0 depending on the seven carbonaceous aerosol models used in OMAERUV. The resulting AAE's are therefore consistent with existing measurements and with more recently reported observations over the Amazon Basin (Rizzo et al., 2011). Using the selected model of near UV spectral absorption a new set of look up tables was calculated, and used in a research version of the algorithm to carry out the retrievals over the Amazon Basin.

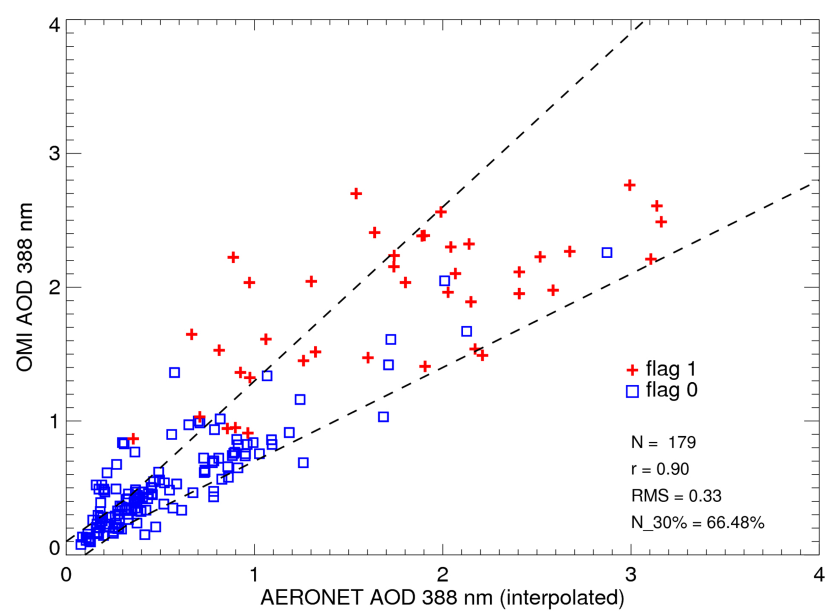

Fig. 5. Comparison of the new OMAERUV retrieval of aerosol optical depth (y-axis) with that of AERONET (x-axis) at $388 \mathrm{~nm}$ for the biomass burning region of South America. OMI data with flag 0 (square) and flag 1 (plus sign) were used in the comparison. The dashed lines are pre-calculated uncertainty (larger of 0.1 or $30 \%$ ) in the OMI AOD retrieval.

\section{Evaluation of new OMAERUV aerosol retrievals}

\subsection{AOD comparison}

As demonstrated in Sect. 4.1, an increase in the assumed spectral dependence of aerosol absorption (or AAE) in the forward calculations would reduce the magnitude of retrieved AOD and thus may reduce the observed large bias between the satellite derived and the ground-based observations. Figure 5 compares the new OMAERUV retrieval of AOD at $388 \mathrm{~nm}$ with the ground-based observations for the seven AERONET sites considered in the study. Note that this assessment includes all retrievals with quality flag 0 and flag 1 for which the measured reflectivity was less than $20 \%$. This largely eliminates the possibilities of the presence of sub-pixel clouds in given OMI pixels. Unlike the original comparison (Fig. 2), the new validation analysis shows a significantly improved agreement between OMAERUV results and AERONET measurements. The improvement is more significant for the previously labeled flag 1 data for which the new AOD is much better aligned with the groundtruth. About $70 \%$ of total retrievals with the current quality flag 0 and 1 now fall within the pre-estimated uncertainty against $25 \%$ retrievals within uncertainty noted in the standard OMAERUV-AERONET comparison (see Fig. 2). The remaining cases of AOD over-estimation are likely to be a result of either sub-pixel cloud contamination or smoke layers located above clouds. Note that little change in the retrieval accuracy of weakly or non-absorbing aerosol data (flag 0 ) has taken place. A close examination of the validation analyses using the BC (Fig. 2) and OC (Fig. 5) assumptions show that for AOD values less than 0.5 there is very little difference 

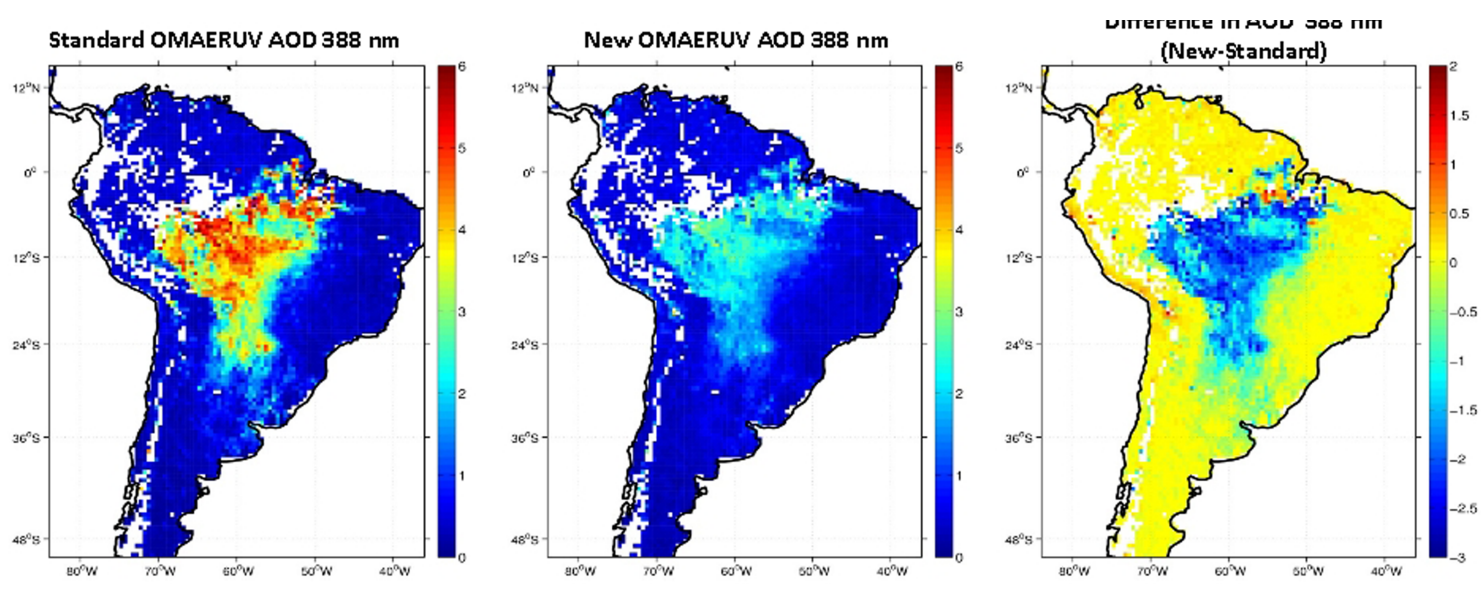

Fig. 6. Spatial distribution of monthly mean aerosol optical depth for September 2007 derived from the standard OMAERUV aerosol product (left panel) and new proposed retrieval (middle panel). The absolute difference between them is shown in right panel. All three distributions are at $0.5^{\circ}$ by $0.5^{\circ}$ resolution.

between the two model representations. For AOD values larger than about 1.0 the use of the colored aerosol assumption does a better job than the grey aerosol approximation yielding a large improvement in retrieval accuracy. An analysis of Fig. 4 reveals that the assumption of AAE of 2.67 (or $20 \%$ relative spectral dependence in spectral absorption) brings a relative percent change of about $65-70 \%$ in AOD lower as well as higher aerosol load with reference to the case of AAE equals 1.0. However, the resulting absolute change is dependent on the magnitudes of AOD where larger change occurs at higher values of AOD. This is probably the reason why the largest improvement in the retrieval of AOD appears to occur at larger values of AOD.

The left panel of Fig. 6 shows the spatial distribution of standard OMAERUV monthly mean AOD (at $0.5^{\circ}$ by $0.5^{\circ}$ resolution) at $388 \mathrm{~nm}$ for September 2007 over South America. The monthly composite was computed from the current OMAERUV aerosol Level-2 retrieval with quality flag 0 and 1. Very high values of AOD $(\sim 6)$ over the central Amazonia region indicates intense loading of smoke which also extends in the eastward as well as southward directions. Note that the spatial pattern of aerosols over the western side follows the topography of the Andes which act as a barrier and does not allow smoke to transverse to the other side. The center panel of Fig. 6 shows the spatial distribution of new OMAERUV AOD $(388 \mathrm{~nm})$ retrieved with the new smoke models. The new retrievals of AOD are significantly lower in magnitude than that of the standard OMI product with similar spatial distribution. The right panel shows the difference in AOD (new-standard OMAERUV) where a large reduction in the magnitudes of AOD is clearly noticeable.

\subsection{SSA comparison}

Figure 7 shows the comparison of OMAERUV (both standard and new retrieval) and AERONET retrieved SSA. OMAERUV-retrieved values are converted to $441 \mathrm{~nm}$ by performing interpolation between OMI reported 388 and $500 \mathrm{~nm}$ values to compare them with AERONET inversions available at $440 \mathrm{~nm}$. The interpolated SSA at $441 \mathrm{~nm}$ was found to be lower than the $388 \mathrm{~nm}$ retrievals as expected. This assumption of black carbon and organics as dominant components of smoke models results in SSA spectra in which absorption increases from near-UV to visible to near-IR. This is also consistent with the findings of other ground-based observations (Russell et al., 2010). With the implementation of the new smoke models, the new SSA retrievals are found to be higher than the standard OMAERUV retrievals. As a result, about $70 \%$ of new OMAERUV retrievals agree within the estimated uncertainty of the AERONET inversion $( \pm 0.03)$ as opposed to $37 \%$ when using the standard gray aerosols assumption.

\subsection{Performance of standard and new OMAERUV aerosol algorithm over other regions}

The effect of using the new colored smoke aerosol models was examined in regions other than the Amazon Basin. Biomass burning is a major anthropogenic source of gaseous and particulate matter over the southern African region (Formenti et al., 2003; Eck et al., 2003). The biomass burning season in the central Africa starts in June at about $10^{\circ} \mathrm{S}$ and persists through August. An AERONET sunphotometer installed at Mongu $\left(-15.254^{\circ} \mathrm{S}, 23.151^{\circ} \mathrm{E}\right)$ provides a long record (from 1995 to 2007) of aerosol properties. The other region of interest is the Indo-Gangetic Plain (IGP), where the biomass burning is known to be a major source of aerosols during winter (October-January) (Jethva et al., 2005, 2007). 


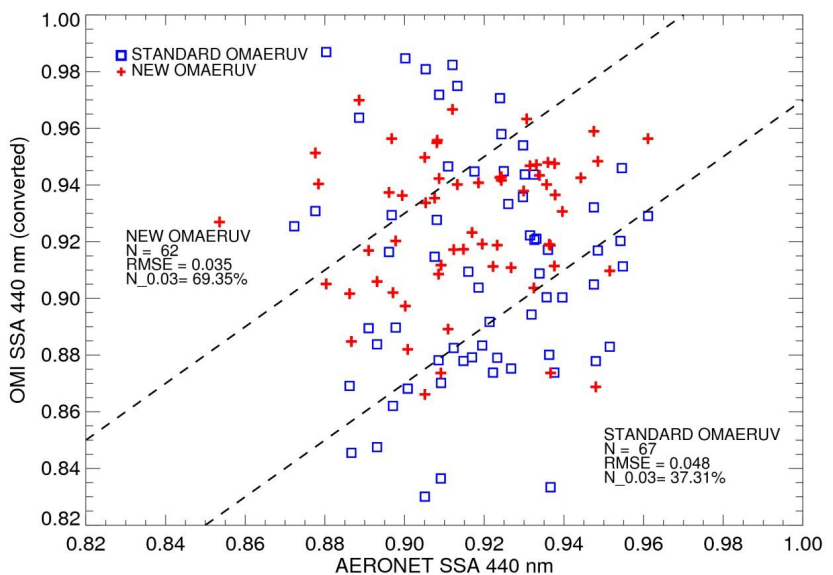

Fig. 7. Comparison of the OMI standard (square) and new (plus sign) single-scattering albedo retrievals (converted to $441 \mathrm{~nm}$ ) with the equivalent AERONET inversions over the biomass burning sites in South America for the period 2004-2008. Dashed lines are the uncertainty of \pm 0.03 in the AERONET inversion.

This region is unique in terms of its surrounding Himalayan topography, weather pattern, and aerosol seasonality. The multiyear aerosol data from the AERONET sunphotometer at Kanpur $\left(26.45^{\circ} \mathrm{N}, 80.35^{\circ} \mathrm{E}\right)$ shows that the aerosol optical depth (at $500 \mathrm{~nm}$ ) ranges between $0.5-0.8$ during the winter months which are associated with relatively larger Extinction Angstrom Exponent (EAE > 1). In addition to the local sources, transported aerosols from other parts of this region also influence the aerosol properties measured by AERONET at Kanpur. MODIS-derived fine mode fraction and TOMSand OMI-derived aerosol index show a widespread and persistent layer of smoke during winter over the region. Due to the influence of biomass burning aerosols and availability of good quality AERONET data, the Mongu and Kanpur AERONET sites, serve as a good test bed for evaluating the current and new assumptions of the spectral aerosol absorption assumed in the OMAERUV retrieval.

Figure 8 compares the co-located AOD retrieved by the standard (squares) and new (pluses) OMAERUV algorithm with AERONET at Mongu and Kanpur. The OMAERUV retrievals with aerosol type identified as smoke are compared with AERONET. Clearly, the AOD retrievals over-estimated in the standard algorithm are significantly reduced in magnitudes such that they fall within the expected uncertainty. Overall, the AODs retrieved with the new carbonaceous models are in better agreement with those of AERONET. The root-mean-square error and percentage of pixels that fall within the expected uncertainty improve significantly. While the RMSE decreases from 0.70 to 0.25 , the percentage of pixels falling within expected uncertainty goes up from $40 \%$ to $56 \%$. The improvement in the retrieval AOD at Kanpur and Mongu was mainly observed during the months of October and August, respectively when these two regions are known to be influenced by the biomass burning. While the largest

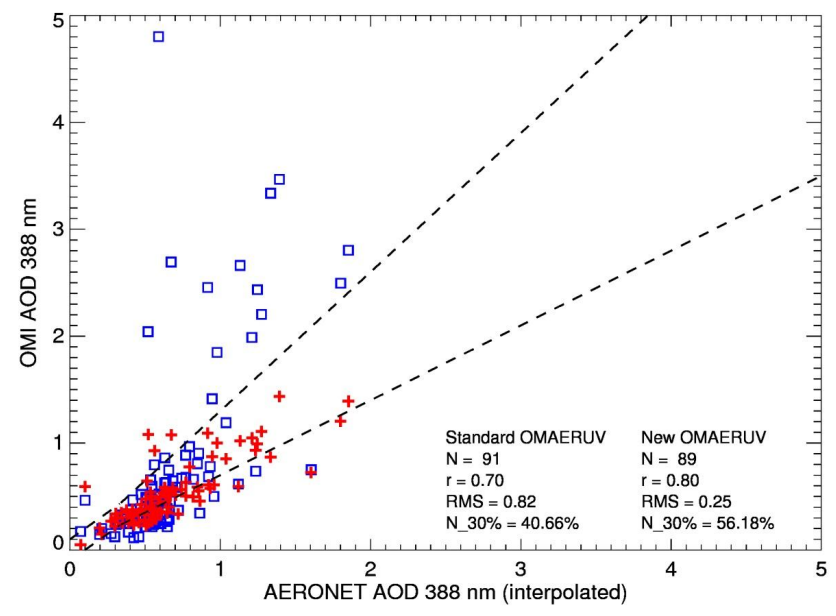

Fig. 8. Comparison of aerosol optical depth at $388 \mathrm{~nm}$ retrieved by standard (squares) and new (pluses) OMAERUV aerosol algorithm with the AERONET measurements at Mongu $\left(-15.254^{\circ} \mathrm{S}\right.$, $\left.23.151^{\circ} \mathrm{E}\right)$ and $\operatorname{Kanpur}\left(26.45^{\circ} \mathrm{N}, 80.35^{\circ} \mathrm{E}\right)$ for the period 20042008.

improvement in the AOD retrieval is obtained at larger values, a little effect is observed at lower values of optical depth. This is consistent with the OMI-AERONET comparison noticed in the case of biomass burning region in South America.

\section{Conclusions}

The OMI instrument onboard NASA's AURA satellite retrieves the columnar total aerosol optical depth and singlescattering albedo and aerosol absorption optical depth simultaneously at near-UV wavelengths operationally over the globe. Since the space-based inversions are based on several assumptions made in the retrieval process, an assessment of the accuracy of these inversions is required. In this paper, we evaluated the OMAERUV products of AOD and SSA against the equivalent measurements made by AERONET over the biomass burning regions of South America, central Africa, and northern India. The current version of the OMI aerosol algorithm tended to over-estimate AOD significantly at near-UV wavelengths for higher aerosol loading (AOD at $388 \mathrm{~nm}>1$ ), when absorption at UV wavelengths also become large as evident from larger magnitudes of UV-aerosol index. The standard OMAERUV algorithm assumes no spectral dependence in absorption between 354 and $388 \mathrm{~nm}$ for biomass burning aerosols. Driven by the theoretical calculations and ground-based evidences on the spectral aerosol absorption (or AAE), a new set of aerosol retrievals were carried out using OMI measurements with the assumed wavelength dependent absorption that follows $\lambda^{-2.5 \text { to }-3.0}$ between 354 and $388 \mathrm{~nm}$. The new retrievals of AOD were found to be in much better agreement with those of AERONET over selected sites. A large improvement in the retrieval of AOD occurs for measurements 
with higher reflectivity which is associated with large aerosol loading and enhanced AI. Due to larger reflectivity at nearUV wavelengths, these conditions are currently reported with degraded quality flag of 1 . However, an improvement in the AOD retrieval with new assumption and coincident OMIMODIS analysis provide necessary justification for these retrievals to be reported as high quality retrievals. In addition, the single-scattering albedo at $388 \mathrm{~nm}$ was also retrieved with better accuracy. This paper suggests that there clearly is a need to incorporate the spectral dependence of absorption at UV wavelengths that accounts for the presence of organic carbon in the biomass burning aerosols in the future version of the OMAERUV aerosol retrieval algorithm. Since the presence of organics not just modifies the spectral absorption in the near-UV, but also affects the absorption at visible wavelengths, it is recommended that a similar analysis be carried out to examine the sensitivity to the presence of organics in carbonaceous aerosols in the visible region used for the AOD retrieval for sensors such as MODIS and MISR.

The use of limited ground-based information on the spectral dependence of aerosol absorption and resultant improvement in the retrieval of OMAERUV AOD and SSA at nearUV wavelengths achieved with the new smoke models over South America, central Africa, and northern India, indicate the presence of organics in biomass burning aerosols over these regions. The present study is probably the first satellite-based assessment that provides an evidence of the strong wavelength-dependent absorption in the near-UV region, which is a proxy for the presence of organic aerosols, through OMI-AERONET comparison. In addition to suggesting significant improvement in the retrieval of aerosol properties from OMI, the present study also demonstrates the sensitivity of near-UV measurements to the chemical composition of biomass burning aerosols.

The association between the aerosol types and related spectral aerosol absorption (or AAE) has been revealed by several important studies in the past decade. Though, in general, the spectral dependence of absorption can be approximated by a single value of $\mathrm{AAE}$, it may be different in the near-UV region than in the visible. For instance, the organics-contained carbonaceous aerosols exhibit a steeper gradient in absorption in the UV region which provides an enhanced spectral signal that can be exploited for the identification of organics and black carbon. A possible approach would be to use AERONET-measured AODs to constraint two-channel OMAERUV retrieval for the derivation of imaginary indices and subsequently AAOD and AAE at near-UV wavelengths. This should be explored further in detail.

Acknowledgements. We thank NASA's GES-DISC and OMI aerosol research team for their free online support of OMI/OMAERUV aerosol database. We also thank Brent Holben and other co-PI for establishing and maintaining AERONET sites whose data was used in this study.

Edited by: M. Van Roozendael

\section{References}

Ahn, C., Torres, O., and Bhartia, P. K.: Comparison of Ozone Monitoring Instrument UV aerosol products with Aqua/Moderate Resolution Imaging Spectroradiometer and Multiangle Imaging Spectroradiometer observations in 2006, J. Geophys. Res., 113, D16S27, doi:10.1029/2007JD008832, 2008.

Andreae, M. O. and Gelencsér, A.: Black carbon or brown carbon? The nature of light-absorbing carbonaceous aerosols, Atmos. Chem. Phys., 6, 3131-3148, doi:10.5194/acp-6-3131-2006, 2006.

Bergstrom, R. W., Russell, P. B., and Hignett, P.: Wavelength dependence of the absorption of black carbon particles: Predictions and results from the TARFOX experiment and implications for the aerosol single scattering albedo, J. Atmos. Sci., 59, 567-577, 2002.

Bergstrom, R. W., Pilewskie, P., Russell, P. B., Redemann, J., Bond, T. C., Quinn, P. K., and Sierau, B.: Spectral absorption properties of atmospheric aerosols, Atmos. Chem. Phys., 7, 5937-5943, doi:10.5194/acp-7-5937-2007, 2007.

Bond, T.: Spectral dependence of visible light absorption by carbonaceous particles emitted from coal combustion, Geophys. Res. Lett., 28, 4075-4078, 2001.

Bond, T. C. and Bergstrom, R. W.: Light absorption by carbonaceous particles: An investigative review, Aerosol Sci. Tech., 40, 27-67, 2006.

Chand, D., Guyon, P., Artaxo, P., Schmid, O., Frank, G. P., Rizzo, L. V., Mayol-Bracero, O. L., Gatti, L. V., and Andreae, M. O.: Optical and physical properties of aerosols in the boundary layer and free troposphere over the Amazon Basin during the biomass burning season, Atmos. Chem. Phys., 6, 2911-2925, doi:10.5194/acp-6-2911-2006, 2006.

de Graaf, M., Stammes, P., Torres, O., and Koelemeijer, R. B. A.: Absorbing Aerosol Index: Sensitivity analysis, Application to GOME and comparison with TOMS, J. Geophys. Res., 110, D01201, doi:10.1029/2004JD005178, 2005.

Dubovik, O. and King, M.: A flexible inversion algorithm for retrieval of aerosol optical properties from sun and sky radiance measurements, J. Geophys. Res., 105, 20673-20696, 2000.

Eck. T. F., Holben, B. N., Ward, D. E., Mukelabai, M. M., Dubovik, O., Smirnov, A., Schafer, J. S., Hsu, N. C., Piketh, S. J., Queface, A., Le Roux, J., Swap, R. J., and Slutsker, I.: Variability of biomass burning aerosol optical characteristics in southern Africa during the SAFARI 2000 dry season campaign and a comparison of single scattering albedo estimates from radiometric measurements, J. Geophys. Res., 108, 8477, doi:10.1029/2002JD002321, 2003.

Eck, T. F., Holben, B. N., Slutsker, I., and Setzer, A.: Measurements of irradiance attenuation and estimation of aerosol single scattering albedo for biomass burning aerosols in Amazonia, J. Geophys. Res., 103, 31865-31878, 1998.

Formenti, P., Elbert, W., Maenhaut, W., Haywood, J., Osborne, S., and Andreae, M. O.: Inorganic and carbonaceous aerosols during the Southern African Regional Science Initiative (SAFARI 2000) experiment: Chemical characteristics, physical properties, and emission data for smoke from African biomass burning, J. Geophys. Res., 108, 8488, doi:10.1029/2002JD002408, 2003.

Guyon, P., Graham, B., Beck, J., Boucher, O., Gerasopoulos, E., Mayol-Bracero, O. L., Roberts, G. C., Artaxo, P., and Andreae, M. O.: Physical properties and concentration of aerosol par- 
ticles over the Amazon tropical forest during background and biomass burning conditions, Atmos. Chem. Phys., 3, 951-967, doi:10.5194/acp-3-951-2003, 2003.

Herman, J. R. and Celarier, E.: Earth surface reflectivity climatology at 340 and $380 \mathrm{~nm}$ from TOMS data, J. Geophys. Res., 102, 12059-12076, 1997.

Herman, J. R., Bhartia, P. K., Torres, O., Hsu, C., Seftor, C., and Celarier, E.: Global distribution of UV-absorbing aerosols from Nimbus 7/ TOMS data, J. Geophys. Res., 102, 16911-16922, 1997.

Hoffer, A., Gelencsr, A., Guyon, P., Kiss, G., Schmid, O., Frank, G. P., Artaxo, P., and Andreae, M. O.: Optical properties of humic-like substances (HULIS) in biomass-burning aerosols, Atmos. Chem. Phys., 6, 3563-3570, doi:10.5194/acp-6-3563-2006, 2006.

Holben, B. N., Eck, T., Slutsker, I., Tanre', D., Buis, J. P., Setzer, A., Vermote, E., Reagon, J. A., Kaufman, Y. J., Nakajima, T., Lavenu, F., Jankowiak, I., and Smirnov, A.: AERONET-A federated instrument network and data archive for aerosol characterization, Remote Sens. Environ., 66, 1-16, 1998.

Jethva, H., Satheesh, S. K., and Srinivasan, J.: Seasonal variability of aerosols over the Indo-Gangetic basin, J. Geophys. Res., 110, D21204, doi:10.1029/2005JD005938, 2005.

Jethva, H., Satheesh, S. K., and Srinivasan, J.: Evaluation of Moderate-Resolution Imaging Spectroradiometer (MODIS) Collection 004 (C004) aerosol retrievals at Kanpur, Indo-Gangetic Basin, J. Geophys. Res., 112, D14216, doi:10.1029/2006JD007929, 2007.

Kahn, A. R., Gaitley, B. J., Martonchik, J. V., Diner, D. J., and Crean, K. A.: Multiangle Imaging Spectroradiometer (MISR) global aerosol optical depth validation based on 2 years of coincident Aerosol Robotic Network (AERONET) observations, J. Geophys. Res., 110, D10S04, doi:10.1029/2004JD004706, 2005.

Kaufman, Y. J., Tanre', D., Remer, L. A., Vermote, E. F., Chu, A., and Holben, B. N.: Operational remote sensing of tropospheric aerosol over the land from EOS-MODIS, J. Geophys. Res., 102, 17051-17067, 1997.

Kirchstetter, T. W., Novakov, T., and Hobbs, P. V.: Evidence that the spectral dependence of light absorption by aerosols is affected by organic carbon, J. Geophys. Res., 109, D21208, doi:10/1029/2004JD004999, 2004.

Kline, J., Huebert, B., Howell, S., Blomquist, B., Zhuang, J., Bertram, T., and Carrilo, J.: Aerosol composition and size versus altitude measured from the C-130 during ACE-Asia, J. Geophys. Res., 109, D19S08, doi:10.1029/2004JD004540, 2004.

Koren, I., Remer, L. A., and Longo, K.: Reversal of trend of biomass burning in the Amazon, Geophys. Res. Lett., 34, L20404, doi:10.1029/2007GL031530, 2007

Krotkov, N., Bhartia, P. K., Slusser, J., Labow, G., Eck, T., and Holben, B. N.: Aerosol Ultraviolet Absorption Experiment (2002 to 2004), Part 2: Absorption Optical Thickness, refractive Index, and Single Scattering Albedo, Opt. Eng. 44, 041005-01, 2005.
Levelt, P. F., Hilsenrath, E., Leppelmeier, G. W., van den Ooord, G. H. J., Bhartia, P. K., Taminnen, J., de Haan, J. F., and Veefkind, J. P.: Science objectives of the Ozone Monitoring Instrument, IEEE Trans. Geosci. Remote Sens., 44, 1093-1101, 2006.

Levy, R. C., Remer, L. A., Mattoo, S., Vermote, E., and Kaufman, Y. J.: Second-generation algorithm for retrieving aerosol properties over land from MODIS spectral reflectance, J. Geophys. Res., 112, D13211, doi:10.1029/2006JD007811, 2007.

Martins, J. V., Artaxo, P., Liousse, C., Reid, J. S., and Hobbs, P. V.: Effects of black carbon content, particle size and mixing on light absorption by aerosol particles from biomass burning in Brazil, J. Geophys. Res., 103, 32041-32050, 1998.

Reid, J. S., Hobbs, P. V., Ferek, R. J., Blake, D. R., Martins, J. V., Dunlap, M. R., and Liousse, C.: Physical, chemical, and optical properties of regional hazes dominated by smoke in Brazil, J. Geophys. Res., 103, 32059-32080, 1998.

Remer, L. A., Kaufman, Y. J., D.Tanre', Mattoo, S., Chu, D. A., Martins, J. V., Li, R. R., Ichoku, C., Levy, R. C., Kleidman, R. G., Eck, T. F., Vermote, E., and Holben, B. N.: The MODIS algorithm, products and validation, J. Atmos. Sci., 62, 947-973, 2005.

Rizzo, L. V., Correia, A. L., Artaxo, P., Procópio, A. S., and Andreae, M. O.: Spectral dependence of aerosol light absorption over the Amazon Basin, Atmos. Chem. Phys., 11, 8899-8912, doi:10.5194/acp-11-8899-2011, 2011.

Russell, P. B., Bergstrom, R. W., Shinozuka, Y., Clarke, A. D., DeCarlo, P. F., Jimenez, J. L., Livingston, J. M., Redemann, J., Dubovik, O., and Strawa, A.: Absorption Angstrom Exponent in AERONET and related data as an indicator of aerosol composition, Atmos. Chem. Phys., 10, 1155-1169, doi:10.5194/acp10-1155-2010, 2010.

Torres, O., Bhartia, P. K., Herman, J. R., Ahmad, Z., and Gleason, J.: Derivation of aerosol properties from satellite measurements of backscattered ultraviolet radiation: Theoretical basis, J. Geophys. Res., 103, 17099-17110, 1998.

Torres, O., Bhartia, P. K., Herman, J. R., Sinyuk, A., Ginoux, P., and Holben, B.: A long-term Record of aerosol optical depth from TOMS observations and comparison to AERONET measurements, J. Atmos. Sci., 59, 398-413, 2002.

Torres, O., Tanskanen, A., Veihelmann, B., Ahn, C., Braak, R., Bhartia, P. K., Veefkind, P., and Levelt, P.: Aerosols and surface UV products from Ozone Monitoring Instrument observations: An overview, J. Geophys. Res., 112, D24S47, doi:10.1029/2007JD008809, 2007.

Torres, O., Chen, Z., Jethva, H., Ahn, C., Freitas, S. R., and Bhartia, P. K.: OMI and MODIS observations of the anomalous 20082009 Southern Hemisphere biomass burning seasons, Atmos. Chem. Phys., 10, 3505-3513, doi:10.5194/acp-10-3505-2010, 2010.

Venkataraman, C., Habib, G., Eiguren-Fernandez, A., Miguel, A. H., and Friedlander, S. K.: Residential biofuels in south Asia: Carbonaceous aerosol emissions and climate impacts, Science, 307, 1454-1456, 2005. 